\title{
ANÁLISIS PRELIMINAR DE LA JURISPRUDENCIA DE LA CORTE SUPREMA SOBRE DAÑOS MORALES EN CAUSAS POR INCUMPLIMIENTOS CONTRACTUALES CIVILES DE LOS AÑOS 2002 A $2007^{*}$
}

\author{
PRELIMINARY ANALYSIS OF THE SUPREME COURT'S \\ JURISPRUDENCE ABOUT NON-PECUNIARY LOSS IN BREACH OF \\ CONTRACT CIVIL CASES FROM 2002 TO 2007
}

\section{MARCELO BARRIENTOS ZAMORANO*}

\begin{abstract}
RESUMEN: La reparación integral del daño consagrado en los artículos 1556; 1558; 2314 y 2329 del Código Civil (en adelante CC), y que es reconocido por parte de la doctrina como un principio de responsabilidad general, está muy lejos de serlo en la realidad de nuestros tribunales.

En las siguientes páginas se expondrá el resultado preliminar de la investigación realizada en la Excelentísima Corte Suprema, particularmente en el "Archivo de Sentencias de la Excelentísima Corte Suprema de Justicia" (en adelante ASECS), sobre la indemnización del daño moral por incumplimientos contractuales civiles. Se utilizó tal archivo para acceder a las sentencias comprendidas entre los años 2002 a 2007.
\end{abstract}

Palabras clave: daño moral, incumplimiento contractual, jurisprudencia.

ABSTRACT: The integral reparation of the consecrated loss in articles 1556; 1558; 2314 and 2329 of the Civil Code, (in the following CC), and which is recognized by the part of the doctrine principle of general responsibility, is still a long way off from being so in the reality of our tribunals.

In the following pages the preliminary investigation of the Supreme Court will be discussed, in particular in the "Archive of Sentences in the Supreme Court of Justice" (in the following ASECS), about non-pecuniary loss in breach of contracts. The following archive will be used to gain access to the sentencing which took place between 2002 and 2007.

Key words: non-pecuniary loss, breach of contract, jurisprudence.

\footnotetext{
* Este trabajo forma parte del Proyecto Límite 01/2009: "La valoración de los daños morales en la indemnización de perjuicios por incumplimiento contractual civil", en que el autor es investigador responsable. Este concurso fue adjudicado por la Vicerrectoría Adjunta de Investigación y Doctorado (VRAID) de la Pontificia Universidad Católica de Chile y cuenta también con el apoyo de la Facultad de Derecho de la Pontificia Universidad Católica de Chile.

** Doctor en Derecho con mención "Doctor Europeus", Universidad de Salamanca, España. Magíster en Derecho de la Empresa, Pontificia Universidad Católica de Chile. Profesor de Derecho Civil de la Pontificia Universidad Católica de Chile. Correo electrónico: mhbz@uc.cl
} 


\section{INTRODUCCIÓN}

El proyecto de investigación tuvo su fuente de información en el ASECS. En este registro se encuentran los libros copiadores de sentencias de la Excelentísima Corte Suprema. Ahí cualquier persona encontrará todas las sentencias pronunciadas por el máximo tribunal del país, en orden cronológico y diferenciado por materias civiles, penales y laborales. Lugar importante para cualquier investigador ya que en los portales jurídicos nacionales, disponibles en Internet, no se encuentran reproducidos todos los fallos que dictan nuestros tribunales sino solo algunos que son escogidos con criterios unilaterales.

En la mayoría de los casos, lo que sería deseable en todos, en el ASECS se agregan las sentencias de primer y segundo grado en cada causa, aunque es de rigor mencionar que toda búsqueda se vuelve rudimentaria al tener que estudiar fajo por fajo las sentencias en diferentes legajos que intimidan y pueden llegar a desalentar hasta el más entusiasta investigador.

\section{LAS DOCTRINAS CHILENAS QUE RECONOCEN EL DAÑO MORAL EN MATERIA CONTRACTUAL}

El reconocimiento en Chile de la indemnización del daño moral en materia contractual ha sido extensamente debatido en la doctrina nacional, y es bastante clara de la lectura de ella una mirada, en general, favorable a su acogimiento amplio en materia contractual $^{1}$. Esto pese a que es discutible si el artículo 1556 del Código Civil sea tan amplio en su interpretación como para acoger el daño moral en materia contractual, como sí lo son el artículo 2314 o el 2329 del mismo cuerpo legal.

No cabe la menor duda que la falta en gran parte del siglo XX del reconocimiento del daño moral en materia contractual como partida indemnizable estaba influenciada por la falsa creencia de que Alessandri habría sostenido que el daño moral no era reparable dentro del incumplimiento del contrato ${ }^{2}$. Este error de apreciación, apuntado por algunos autores, ha permitido asentar en gran cantidad de fallos, hasta el día de hoy, la inexistencia del daño moral en materia contractual basada en este supuesto argumento falaz de tal autoridad doctrinal chilena ${ }^{3}$.

En cualquier caso, creemos que la hipertrofia de la responsabilidad extracontractual ha tenido y tiene bastante que ver con el casi nulo reconocimiento del daño moral en sede contractual civil por parte de la Corte Suprema en el período estudiado en esta investigación. El concepto amplio de daño del artículo 2314 y 2329 del CC han posibilitado tal extensión. La norma del artículo 1556, a la que siempre se le ha dado una clara faz patrimonial, pareciera cerrar la puerta a un reconocimiento amplio del daño extrapa-

\footnotetext{
1 TAPIA (1941) p. 292; BARros (2006) pp. 230 y ss.; Corral (2003) pp. 167 y ss., entre muchos más y de manera abrumadoramente mayoritaria.

2 Rodríguez (1999) pp. 315 y 316; ALESSANDri (1943) pp. 226 y 227.

3 JANA y TAPIA, (2002) p. 177.
} 
trimonial y la salida a tal espinuda cuestión nos parece que debe ser abordada a partir del artículo 1558 por razones hermenéuticas e históricas, como hemos tenido oportunidad de señalar antes en otros trabajos ${ }^{4}$.

El advenimiento de una progresiva constitucionalización del Derecho civil para ciertos autores ${ }^{5}$, también habría posibilitado que la infracción de deberes contractuales se tome con referencia a los bienes de la personalidad, lo que abriría la puerta a su indemnización ${ }^{6}$. Así, el incumplimiento contractual, sobre todo referido a aflicciones y perturbaciones de carácter sicológico y que se producen como consecuencia de un incumplimiento, ha tratado de ser justificado en su indemnización dentro de la reparación de los perjuicios. En la visión comparada más moderna esto ya no es discutible, porque si bien la noción de Derecho de daños partió de la protección patrimonial, hoy se atiende a la persona que el Derecho protege con independencia de sus bienes e intereses económicos.

Resulta casi imposible desprender la indemnización del daño moral en materia contractual civil de la buena fe, precisamente porque se produce un daño, un atentado a la esfera subjetiva de aquel acreedor que confió en que el contrato se cumpliría, lo que por cierto ha de dar lugar a una indemnización.

Si bien pareciera en doctrina superada la visión reduccionista de la patrimonialidad de la prestación, no es menos cierto que su importancia no ha menguado, salvo escasos fallos del período estudiado, en el criterio de los jueces que fallaron las causas analizadas en nuestro trabajo de investigación.

No podemos calificar ni siquiera de vacilante el reconocimiento del daño moral en materia contractual civil por la Corte Suprema en el período estudiado, sino más bien, como excepcionalísimo.

La doctrina jurisprudencial mayoritaria en Chile sigue proclive a que se distinga en el daño moral dentro del incumplimiento de un contrato, entre el llamado daño moral "puro" o "meramente moral" del daño moral con consecuencias pecuniarias ${ }^{7}$.

Del estudio realizado a las sentencias de la Corte Suprema, se desprenden titubeos por parte de los sentenciadores frente a la importancia o entidad jurídica de ciertos incumplimientos contractuales civiles y su habilidad para causar daños en el ámbito extrapatrimonial de un acreedor que los solicite en su demanda. Cuesta ver incorporado a esta esfera elementos de responsabilidad civil que posibiliten su indemnización seria y jurídicamente relevante. De hecho, el daño moral en incumplimientos contractuales no aparece como inherente al incumplimiento contractual civil, sino solo en casos excepcionales y raros.

\footnotetext{
${ }^{4}$ BARRIENTOS (2007) pp. 7 y ss.

5 Domínguez ÁGuila (1990) p. 154

6 "...estamos con aquellos que conciben el daño moral del modo más amplio posible, incluyendo alli todo daño a la persona en si misma -física o psíquica-, como todo atentado contra sus intereses extrapatrimoniales. Comprende pues el daño moral todo menoscabo del cuerpo humano, considerado como un valor en si y con independencia de sus alcances patrimoniales (...) En suma, el daño moral estará constituido por el menoscabo de un bien no patrimonial que irroga una lesión a un interés moral por una que se encontraba obligada a respetarlo". Dominguez Hidalgo (2002) pp. 83 y ss.

7 Alessandri (1943) p. 224.
} 
Es fácilmente comprobable, a partir del estudio de casos realizado, que la indemnización del daño moral o extrapatrimonial en materia contractual los litigantes prefieren alegarla por la vía extracontractual, lugar donde los artículos 2314 y 2329 del CC parecen ser más propicios a la indemnización de este perjuicio, pues reflejan de mejor forma el principio alterum non laedere y los deberes que de él se desprenden. Esta tendencia es, en muchos casos, avalada por el propio juez de instancia y en caso alguno reparado por los tribunales superiores.

En materia de responsabilidad civil, de acuerdo a las modernas teorías, las reglas civiles ordenan indemnizar todo daño causado. El daño indemnizable es uno solo, sea en sede contractual o extracontractual. El hecho de que el daño se manifieste en uno u otro estatuto, se debe a que las obligaciones de estos estatutos, contractual y extracontractual, regirán la resarcibilidad. La resarcibilidad aparece como una nota característica, aunque más bien residual en el daño y su apreciación. No parecen acertados los criterios que enfocan el daño desde la resarcibilidad, ni menos los que pretenden hacer de ella un evento único en cualquier estatuto de responsabilidad. Una cosa es que el daño sea el mismo en cualquier régimen de responsabilidad y otra muy distinta es que se indemnice de la misma manera.

Es absolutamente claro que un daño de carácter económico no puede ser reparado igual que uno de carácter físico, pero ello no es argumento para realizar diferenciación entre ambos daños fundados solo en la reparación de los mismos. Es más, la forma de resarcir los daños producidos a una persona, hoy no están supeditados solo a una compensación en dinero, sino también pueden serlo en especie.

Fueyo señala claramente algo que debiera quedar definitivamente asentado e indisputado en el criterio jurídico que debe seguirse al tratar el problema del daño moral: "Para mi es como un axioma que el concepto jurídico de daños abarca toda forma de daños, esto es, tanto el patrimonial como el extrapatrimonial's. Es claro que esto, a la luz de nuestra investigación, está lejos de ser así en nuestra doctrina jurisprudencial mayoritaria en materia de reparación de daños morales por incumplimiento contractual en materias civiles.

\section{SOBRE EL ESTUDIO EN PARTICULAR Y SUS VARIABLES}

En esta primera etapa del proyecto de investigación se han recopilado fallos en materias contractuales civiles desde el mes de enero de 2002 a diciembre de 2007 en la forma relatada en la introducción de este mismo trabajo. Las conclusiones preliminares son las siguientes.

De los fallos analizados las principales causales de rechazo de la indemnización por daño moral son:

a) El solicitante del daño moral es una persona jurídica, sobre la que no es posible la indemnización del daño moral en materia contractual. 
Es regla general dentro del estudio de los fallos el rechazo a indemnizar daños morales a personas jurídicas, si bien en algunos fallos expresamente el tribunal de primera instancia ha omitido referirse a los fundamentos de tal rechazo.

b) El daño moral no procede en sede contractual.

Dentro de la muestra se ha podido determinar que no existe en realidad un convencimiento estandarizado en cuanto a aceptar o rechazar en daño moral en sede contractual, así un fallo de primera instancia del año 2000, señala en su considerando 100 "Respecto del daño moral, es doctrina mayoritaria de nuestros tribunales que no procede la indemnización de perjuicios fundada en el incumplimiento de una obligación contractual, atendido que según el artículo 1556 del Código Civil, aplicable en la materia, la indemnización proveniente de no haberse cumplido la obligación o haberse cumplido imperfectamente, o haberse retardado su cumplimento, solo comprende el daño emergente y el lucro cesante, por lo que la demanda ha de ser desechada en este extremo".

Los tribunales superiores, tanto en apelación como en casación, desecharon la demanda por otros motivos no atingentes a los perjuicios, en consecuencia, como ocurre en la mayoría de los casos, se pierde la posibilidad de pronunciamiento sobre la procedencia o no de la acción deducida en juicio a título de daño moral en el ámbito de un incumplimiento contractual civil.

Así también un fallo de primera instancia de 2004, que es repetido por otros fallos posteriores, señala en su considerando vigésimo cuarto "que en cuanto al daño moral reclamado por la demandante equivalente a la suma de \$100.000.000, del análisis de los antecedentes y estimándose por este Tribunal que atendido el estatuto de responsabilidad invocado por el reclamante, aquel resulta improcedente por no ser indemnizable el daño moral en el ámbito contractual, sino a la luz de los capitulos habilitantes del artículo 1556 del Código Civil, por lo que menester será desechar su cobro por improcedente".

c) Los tribunales no acogen daño moral por falta de prueba sobre los perjuicios alegados.

Existe cierto consenso en la jurisprudencia que sobre el daño moral rige la regla general del onus probandi, es decir, quien alega el perjuicio debe probar su existencia, incluso en materia contractual para acoger el daño moral en incumplimientos, de acuerdo al artículo 1698 del CC.

En consecuencia, en gran parte de los fallos estudiados se expresa en sus considerandos que no habiéndose rendido probanza alguna al demandante a fin de acreditar los perjuicios cuyo resarcimiento reclama, no habrá lugar en esta parte a la demanda. En razón de lo anterior, no es extraño ver citado el argumento sobre el cual la presunción de daño moral solo se aplica a los casos de responsabilidad extracontractual en que se reclama el "pretium doloris", y en cambio en materia contractual, dichos daños deben probarse por regla general. Esta es, a no dudar, una de las razones principales por las que los litigantes prefieren demandar por responsabilidad extracontractual el daño moral derivado de un incumplimiento contractual, situación que no es reparada por los jueces de instancia en las sentencias que terminan acogiendo las pretensiones incoadas de esta forma en estrados. 
En los fallos analizados las principales causales de aceptación de la indemnización por daño moral en incumplimientos contractuales son difíciles de determinar. Se carece de requerimientos en la prueba del daño moral por las que las partes puedan guiarse, y su ponderación, además de su estimación, no escapa de la discrecionalidad total del tribunal.

Las sentencias, en general, no pasan de la intuición jurídica y de aislados esfuerzos que son más bien visibles en primera instancia en la mayoría de los casos. Creemos que, como ya antes hemos apuntado en otros trabajos sobre la materia, no todo el problema de las indemnizaciones genéricas descansa en las sentencias y sus autores. Del trabajo realizado es claro que sería profundamente injusto endosar toda la responsabilidad por esos fallos a los sentenciadores. Al contrario, también existe una inquietante falta de precisión por parte de los litigantes en la petición de sus demandas por daño extrapatrimonial o moral. Es frecuente ver peticiones genéricas que no diferencian entre los distintos conceptos indemnizatorios. En la mayoría de los casos los litigantes solo mencionan una suma de dinero huérfana de raciocinio en su justificación y súplicas a la discrecionalidad del juez de la causa en atención a los hechos alegados, incluso en relación a la cuantía. Son, lamentablemente comunes en este sentido, solicitudes de sumas desproporcionadamente altas e injustificadas en la demanda y que escasamente se prueban como efectivas más tarde en el proceso, dejándose entregada por los litigantes a presunciones de los hechos materiales alegados o la discrecionalidad del Tribunal a quo. La incerteza del daño no afecta tan solo a su reparación, sino a su cuantía, esto queda bastante claro a estas alturas de la investigación emprendida.

Finalmente, y de manera inevitable, el juicio restringido que se tiene sobre el concepto de daño moral y su prueba, crea problemas procesales. Justamente, se ve afectada la eventual casación de la sentencia, al no haber prueba rendida sobre el daño extrapatrimonial. El juez de acuerdo a los antecedentes del proceso y la equidad cuenta con amplia discrecionalidad para establecerlo y apreciarlo, pero eso no garantiza el éxito de la pretensión deducida. La consecuencia más inmediata, sin duda, es la contracción escalonada de la indemnización sentenciada por el tribunal de primera instancia, en segunda instancia y, finalmente, en la casación en el fondo, lo que no deja de ser una curiosidad, porque nadie se detiene a explicar por qué ocurre esto desde el punto de vista jurídico.

Es necesario recalcar que la investigación emprendida se volvió árida y difusa ya que en la mayor parte de los casos no se podía determinar cuáles eran los motivos por los cuales se aceptaba la indemnización del daño y menos aún lo referente a su graduación o quantum indemnizatorio. En un porcentaje muy elevado de casos queda todo entregado a los jueces de instancia, que al parecer (considerando el avance de la investigación), no han creado parámetros o criterios generales de graduación y cuantía para apreciar el daño moral derivado de incumplimientos contractuales. Se entrega, por el contrario, esta partida a valores subjetivos, que esta investigación intentará dilucidar en un estado posterior de la misma.

En el estado actual de la investigación, es claro que llegados los fallos a conocimiento de la Corte Suprema por el recurso de casación, lamentablemente son rarísimos 
los pronunciamientos extensos sobre daño extrapatrimonial en incumplimientos contractuales civiles. A modo ejemplar, en un fallo de Casación de la Corte Suprema, en causa Rol No 140.612-2003 de fecha tres de julio de dos mil siete, se señala muy escuetamente que "esta Corte ya ha resuelto reiteradamente la procedencia de los daños morales en materia contractual". En lo resolutivo del fallo señalado se expresa la suma de dinero a indemnizar por concepto de daño moral, sin pronunciarse la Corte sobre cuáles son los elementos que tuvieron a la vista los ministros para fallar la indemnización y, sobre todo, para determinar el quantum de la indemnización. Creemos imposible citar un fallo más paradigmático que este y que resume una práctica extendida a la luz de los resultados de esta investigación a día de hoy.

\section{BIBLIOGRAFÍA CITADA}

Alessandri Rodríguez, Arturo (1943): De la Responsabilidad Extracontractual en el Derecho Civil Chileno (Santiago, Imprenta Universitaria, primera edición) 716 pp.

BARros BourIE, Enrique (2006): Tratado de Responsabilidad Extracontractual (Santiago, Editorial Jurídica de Chile, primera edición) 1230 pp.

BARRIENTOS ZAMORANO, Marcelo (2007): Los daños extrapatrimoniales que se previeron o pudieron preverse al tiempo del contrato. Revista Chilena de Derecho, abril 2007, vol. 34, No 1, pp. 7-22.

Corral TalCiani, Hernán (2003): Lecciones de Responsabilidad Civil Extracontractual (Santiago, Editorial Jurídica de Chile, primera edición) 423 pp.

Domínguez ÁGuila, Ramón (1990): "Consideraciones en torno al daño en la responsabilidad civil. Una visión comparatista”, Revista de Derecho de la Universidad de Concepción, No 188: pp. 125-168.

Domínguez Hidalgo, Carmen (1999): "Aspectos modernos de la reparación por daño moral: contraste entre el Derecho Chileno y el Derecho Comparado", Revista de Derecho de la Universidad Católica del Norte, vol. 6: pp. 29-46.

Domínguez Hidalgo, Carmen (1998): "La indemnización por daño moral. Modernas tendencias en el Derecho chileno y Comparado", Revista Chilena de Derecho, vol. 25, No 1, pp. 27-55.

Domínguez Hidalgo, Carmen (1999): "La indemnización por daño moral. Modernas tendencias en el Derecho chileno y Comparado", Revista Chilena de Derecho, vol. 25, No 1, pp. 27-55.

Domínguez Hidalgo, Carmen (2002): El daño moral, Tomo I (1 a edición) (Santiago, Editorial Jurídica de Chile, primera edición).

FueYo, Fernando (1990): Instituciones de Derecho Civil Moderno (Santiago, Editorial Jurídica de Chile) 578 pp.

JANA, Andrés y TAPIA, Mauricio (2004): “Daño moral en la responsabilidad contractual a propósito de un fallo de la Corte Suprema de 5 de noviembre de 2001", Cuadernos de Análisis Jurídico, Temas de Responsabilidad civil, Colección Derecho Privado I, Universidad Diego Portales, pp. 171-209.

Rodríguez Grez, Pablo (1999): Responsabilidad Extracontractual (Santiago, Editorial Jurídica de Chile, primera edición) 505 pp. 
Barrientos Zamorano, Marcelo “ "Análisis preliminar de la jurisprudencia de la Corte Suprema sobre daños..."

TAPIA Rodríguez, Mauricio (2005): Código Civil 1855-2005. Evolución y perspectivas (Santiago, Editorial Jurídica de Chile, primera edición) 471 pp.

TAPIA S., Orlando (1941): De La Responsabilidad Civil Y Delictual Contratante (Concepción, Publicaciones de la Universidad de Concepción, 1941) p. 292. 